\title{
High-Resolution Mapping of Two \\ Broad-Spectrum Late Blight Resistance \\ Genes from Two Wild Species \\ of the Solanum circaeifolium Group
}

\author{
Estelle Verzaux • Gert van Arkel • \\ Vivianne G. A. A. Vleeshouwers • \\ Edwin A. G. van der Vossen • Rients E. Niks • \\ Evert Jacobsen • Jack Vossen • Richard G. F. Visser
}

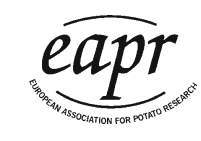

Received: 30 October 2011 / Accepted: 9 May 2012 /

Published online: 10 June 2012

(C) The Author(s) 2012. This article is published with open access at Springerlink.com

\begin{abstract}
High levels of resistance to Phytophthora infestans in Solanum are predominantly based on the gene-for-gene interaction. Identification of hitherto unknown $R$ genes is essential for future pyramiding approaches. This could be achieved either through classic introgression breeding or through cisgenesis and could lead to sustainable control of late blight. Here, we report on the mapping of Rpi-capl and Rpi-qum1, two late blight $R$ genes identified in the wild species Solanum capsicibaccatum and Solanum circaeifolium ssp. quimense, respectively, to very similar positions on the long arm of chromosome 11. Despite the difficulties encountered for marker development, a high-resolution genetic map with cleaved amplified polymorphic sequence markers was constructed. Furthermore, an $R$ gene cluster-directed profiling approach led to the development of markers that closely
\end{abstract}

Electronic supplementary material The online version of this article (doi:10.1007/s11540-012-9213-x) contains supplementary material, which is available to authorized users.

E. Verzaux · G. van Arkel • V. G. A. A. Vleeshouwers • E. A. G. van der Vossen • R. E. Niks •

E. Jacobsen $\cdot$ J. Vossen $\cdot$ R. G. F. Visser $(\bowtie)$

Wageningen UR Plant Breeding, Wageningen University \& Research Centre, PO Box 386, 6700 AJ

Wageningen, The Netherlands

e-mail: richard.visser@wur.nl

E. Verzaux

The Graduate School Experimental Plant Sciences, Wageningen University, Wageningen, The Netherlands

Present Address:

E. A. G. van der Vossen

Keygene N.V., Agro Business Park 90, 6708 PW Wageningen, The Netherlands 
linked to or co-segregated with the Rpi-capl gene. Both $R$ genes are hypothesized to be homologous to the $N$ gene, a toll-interleukin1 receptor-nucleotide-binding siteleucine-rich repeat domain type of $R$ gene to tobacco mosaic virus from tobacco. To confirm this hypothesis, cloning of Rpi-capl and Rpi-quml should be pursued. Cloning would also be instrumental to facilitate the introduction of these valuable $R$ genes into potato crops using cisgenic- and marker-assisted breeding approaches.

Keywords Chromosome $11 \cdot$ Late blight resistance $\cdot N$ resistance gene cluster . Phytophthora infestans $\cdot$ Quimense $\cdot$ Solanum capsicibaccatum $\cdot$ Solanum circaeifolium spp.

\section{Introduction}

The gene-for-gene hypothesis was first proposed by Harold Flor in the 1940s. It is the most studied model explaining plant resistance to pathogens. According to this model, which was later reviewed by the same author (Flor 1971), for each resistance $(R)$ gene of the plant, there is a corresponding avirulence gene in the pathogen. In the past decade, it was found that avirulence is determined by specific pathogen-derived effector proteins (Hogenhout et al. 2009). Recognition of a specific effector by the $\mathrm{R}$ protein will lead to the activation of plant defenses and stop pathogen growth, resulting in a hypersensitive response (HR). The most common class of $R$ genes encodes proteins with two characteristic domains: a nucleotidebinding site (NBS) and a leucine-rich repeat domain (LRR) (Chisholm et al. 2006; Rairdan and Moffett 2007). Roughly, this class of $R$ genes can be divided into two groups, based on the domain present in the $\mathrm{N}$ terminus: $\mathrm{R}$ proteins with a tollinterleukin 1 receptor (TIR) domain in their $\mathrm{N}$ terminus and proteins that do not contain a TIR domain. In plant genomes, these genes tend to occur in clusters containing pseudogenes and functional genes (Michelmore and Meyers 1998). In their review, these authors describe a theory for the evolution of $R$ genes and propose that the presence of complex $R$ gene clusters can explain how plants generate and maintain large numbers of resistance specificities against ever-changing pathogen populations.

The oomycete Phytophthora infestans (Mont.) de Bary, causing late blight in potato, is the most devastating pathogen for potato (Solanum tuberosum) production. Currently, the disease is mainly controlled by chemicals which involve high costs and raises environmental concerns. Past experiences indicate that an effectively durable control, relying on single $R$ genes, is not feasible because of the quick breakdown of the $R$ gene by the rapidly evolving pathogen (McDonald and Linde 2002). Pyramiding several $R$ genes in a single genotype might be an option to more durably fight late blight (Pink 2002; McDowell and Woffenden 2003). A practical way to pyramid several $R$ genes in potato cultivars is through cisgenesis (Schouten et al. 2006; Jacobsen and Schouten 2007; Haverkort et al. 2008). This approach requires the availability of a large number of diverse $R$ genes with complementary spectra of resistance. Resistance spectrum and effector recognition are important aspects to take into account in selecting the most promising $R$ genes for pyramiding to reach durable resistance. 
The genomic region on the distal end of the long arm of chromosome 11 in potato has been characterized as a resistance "hotspot" in a review by Gebhardt and Valkonen (2001), harboring two $R$ genes giving resistance to viruses, one to a nematode and one to a fungus, and two QTL, one giving resistance to potato late blight and one to Erwinia soft rot. Later, one more gene was added to that list: $Y$-1 occurring in $S$. tuberosum subsp. andigena and conferring cell death upon infection with potato virus $Y$ (PVY). One $R$ gene is mapped in the syntenic tomato genomic region, and that is the gene $I$ conferring resistance to Fusarium oxysporum f. sp. lycopersici (Sarfatti et al. 1991). The PVY gene was cloned and is homologous to the $N$ gene from tobacco (Vidal et al. 2002). This $R$ gene-rich genomic region on chromosome 11 appears to be syntenic to the tobacco genome segment containing the $N$ gene (Whitham et al. 1994). The tobacco $N$ gene was one of the first $R$ genes to be cloned; it confers resistance to tobacco mosaic virus, and it encodes a TIR-NB-LRR type of protein. The syntenic $R$ gene cluster in potato contains sequences homologous to the $N$ gene, as was demonstrated by homology in cDNA clones (Hehl et al. 1999), $N$-like specific PCR products, (Hämäläinen et al. 1998; Leister et al. 1996), and BAC-end sequences (Zhang and Gassmann 2007). This $R$ gene-rich region apparently contains a large number of $N$-like sequences, suggesting that the $R$ genes present in this region must be homologous to the $N$ gene. Therefore, we refer to this region as the $N$ cluster.

In a recent study, Jacobs et al. (2010) mapped Rpi-cap1, a gene from the diploid wild Solanum species Solanum capsicibaccatum Cardenas giving resistance to $P$. infestans, on chromosome 11. A repulsion phase marker had homology to the $N$ gene. This $R$ gene is a candidate for genetic fine mapping and cloning as the Rpi-caplcontaining genotype displays high levels of resistance to late blight in the field and has a broad resistance spectrum. Genotypes of $S$. circaeifolium ssp. quimense Hawkes $\&$ Hjerting display similar levels of broad-spectrum resistance, and the late blight $R$ gene occurring in the latter species will be referred to as Rpi-qum1. Both species phylogenetically locate to the diploid series Circaeifolia, endemic in Bolivia (Hawkes and Hjerting 1989). The aim of this study was to fine map the genes Rpi-capl and Rpi-qum1. Large mapping populations were developed and closely linked cleaved amplified polymorphic sequence (CAPS) markers were identified in both populations. Also, a cluster-directed profiling (CDP) approach combined with bulked segregant analysis (BSA) was pursued for Rpi-capl and led to the identification of a marker co-segregating with Rpi-capl.

\section{Materials and Methods}

Plant Material and Mapping Population

Accessions of $S$. capsicibaccatum, $S$. circaeifolium ssp. quimense, and S. circaeifolium ssp. circaeifolium (Table 1) were provided by the Centre of Genetic Resources in Wageningen, The Netherlands. The two resistant genotypes $S$. capsicibaccatum (cap) 536-1 and S. circaeifolium ssp. quimense (qum) 567-1 were selected and were crossed with susceptible plants of $S$. circaeifolium ssp. circaeifolium (crc) 564-3 and crc564-4 to generate intra-specific F1 mapping populations for Rpi-capl and Rpi-qum 1, respectively (Table 2). 
Table 1 List of accessions tested from the wild Solanum section Circaeifolia species $S$. capsicibaccatum (cap) and S. circaeifolium ssp. circaeifolium (crc) and ssp. quimense (qum)

\begin{tabular}{lllll}
\hline Species & Accession & Gene bank & $\begin{array}{l}\text { Number of } \\
\text { genotypes tested }\end{array}$ & $\begin{array}{l}\text { Number of resistant } \\
\text { genotypes }\end{array}$ \\
\hline cap & 535 & CGN18254 & 5 & 0 \\
cap & 538 & CGN18265 & 4 & 0 \\
cap & 335 & CGN18268 & 9 & 0 \\
cap & 261 & BGRC35377 & 5 & 0 \\
cap & 534 & CGN18291 & 5 & 0 \\
cap & 334 & CGN18297 & 5 & 1 \\
cap & $\mathbf{5 3 6}$ & CGN22388 & $\mathbf{2}$ & $\mathbf{1}$ \\
cap & 566 & CGN22767 & 5 & 0 \\
crc & 564 & CGN18133 & 5 & 0 \\
crc & 563 & BGRC27058 & 5 & 5 \\
qum & 340 & CGN18127 & 3 & 1 \\
qum & 341 & CGN18128 & 9 & 8 \\
qum & $\mathbf{5 6 7}$ & CGN18158 & $\mathbf{3}$ & $\mathbf{3}$ \\
qum & 565 & CGN20643 & 5 & 5 \\
\hline
\end{tabular}

Individual genotypes were tested in detached leaf assay for their resistance to P. infestans isolate 90128 . The accessions from which the resistant genotypes of this study originated are indicated in bold

$C G N$ Centre for Genetic Resources, The Netherlands (http://www.cgn.wur.nl/uk/); BGRC Braunschweig Genetic Resource Center

\section{Phytophthora and Disease Test}

The $P$. infestans isolates used in this study which were kindly provided by Prof. Francine Govers and Dr. Geert Kessel from Wageningen University \& Research Centre and Prof. Paul Birch from the James Hutton Institute in Scotland (Table S1). $P$. infestans isolate 90128 was used to screen for resistant genotypes from the accessions $S$. capsicibaccatum and $S$. circaeifolium ssp. quimense. The F1 populations were inoculated with the same isolate to test for the segregation of resistance. The segregants were also tested with four other isolates VK98014, IPO-4282, NL01096, and EC1. The resistance spectrum of the parents was characterized using inoculation with 21 isolates (Table S1).

Table 2 Description of the Rpi-capl and Rpi-qum1 F1 populations

\begin{tabular}{lllllll}
\hline Gene & R parent & S parent & Population size & $R$ & $S$ & Chi-square $\left(\chi^{2}\right)$ \\
\hline Rpi-cap1 & cap536-1 & crc564-3 & 108 & 64 & 44 & $<0.05$ \\
Rpi-qum1 & qum567-1 & crc564-4 & 50 & 25 & 25 & $<0.05$ \\
\hline
\end{tabular}

Segregation of resistance in the detached leaf assay is indicated as: R for resistant and S for susceptible F1 plants. Chi-square test assumed a 1:1 segregation if the resistance is based on one $R$ gene in heterozygous state in the $\mathrm{R}$ parent 
Screening the Solanum series Circaeifolia accessions for resistance to P. infestans isolate 90128 was performed using an in vitro inoculation assay (Huang et al. 2005a). Further resistance screens of selected genotypes were performed according to the detached leaf assay (DLA) protocol (Fig. 1), as described by Vleeshouwers et al. (1999). Depending on their size, the leaves of 5-week-old plants were inoculated with 6 to 10 drops of inoculum containing 50,000 zoospores/ml. After 6 days of inoculation, the leaves were scored as resistant (HR, small necrotic lesions) or as susceptible (large lesions with sporangiophores).

\section{DNA Isolation}

Young leaf tissue was collected from greenhouse grown plants and samples were frozen in liquid nitrogen. The frozen material was homogenized with the Retsch machine (Retsch Inc., Hannover, Germany). Genomic DNA was isolated using either of two different protocols. DNA that needs long storage, like that from the mapping population and the recombinants, was isolated using the cetyltrimethylammonium bromide (CTAB) protocol described by Huang et al. (2005b). DNA that does not require long time storage, like DNA for the screening for recombination events in the population, was isolated using the $\mathrm{NaOH}$ protocol described by Wang et al. (1993).

\section{Marker Development and Map Construction}

Two different approaches were followed to identify additional PCR markers on the long arm of chromosome 11. First, primers deriving from known markers on the long arm of chromosome 11 were screened for CAPS polymorphisms using a set of 24 frequently cutting restriction enzymes. In a second approach, primers were designed on the basis of RH89-039-16 (RH) BAC sequences mapped on the long arm of chromosome 11 in the potato genome sequencing project (http://www.potatogenome.net/). These primers were first tested for amplification on the parents. Potential allele-specific markers were selected that amplified only a fragment in the resistant parent. If a fragment was produced for both parents, the PCR product was screened with a selection of

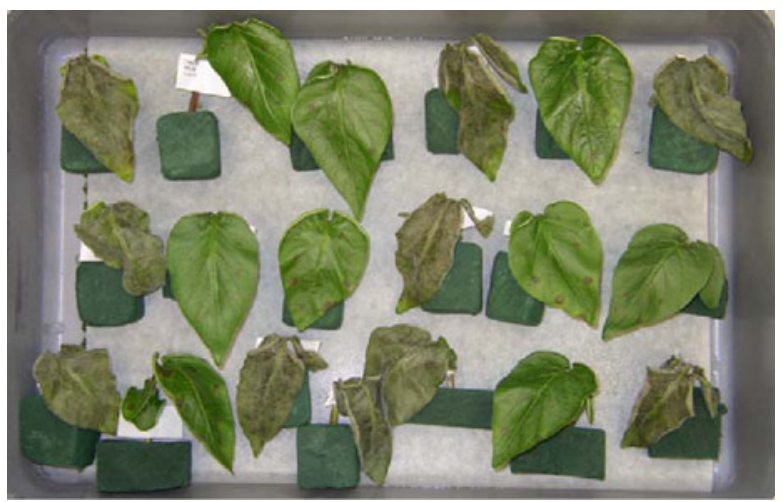

Fig. 1 Detached leaf assay on 19 F1 individuals of Rpi-capl population, 6 days after inoculation with Phytophthora infestans (isolate 90128). The resistant phenotypes stand out as green leaves, the susceptible phenotypes are recognized from their sporulating, brownish, and wrinkled leaves 
restriction enzymes for the identification of a CAPS polymorphism. Successively, polymorphisms occurring between the parents were tested for segregation in the F1 population. Next, a possible association with the resistance phenotype was assessed. Genetic maps were constructed using the recombination frequency between the markers and between the markers and the resistant/susceptible phenotype.

\section{Recombinant Screening}

Seeds from the F1 crosses were sown in 96-well format plant trays in order to facilitate the screen. Two weeks after germination, the second true leaf was harvested and DNA was isolated by following the $\mathrm{NaOH}$ protocol. The markers N127 and T079, flanking Rpicap1, and the markers N127, T081, and ADG2, flanking Rpi-qum1, were applied on the freshly isolated DNA. Eight hundred forty-eight individuals for Rpi-capl and 349 individuals for Rpi-qum1 were screened with these markers. The F1 individuals that showed a recombination between the flanking markers were transplanted to pots. We later isolated DNA using the CTAB method to confirm the recombination. All recombinant plants were tested for resistance phenotypes, using the detached leaf assay and isolate 90128. The recombinants were maintained in in vitro cultures and their phenotype was retested in DLA.

\section{$N$-Like Profiling}

The $N$-like profiling is based on the NBS profiling protocol as described by van der Linden et al. (2004). We designed a total of eight degenerate primers on $N$-like specific sequences, in the TIR, NBS, and LRR domains. Genomic DNA was digested using five different restriction enzymes generating blunt ends. Adaptors were ligated to the restriction ends and a PCR was performed using the $N$-like primers in combination with a fluorescently labeled adaptor primer. Fragments were size-separated and gel images were generated using a LI-COR DNA sequencer (Lincoln, Nebraska, USA). A BSA approach was carried out with bulks of 10 resistant and 10 susceptible nonrecombinant plants. Also, 10 resistant and 10 susceptible recombinant plants were bulked. The identified bulk-specific markers were verified in the F1 individuals of the bulks and were successively tested on the complete population for validation and mapping.

\section{Results}

Resistance in S. capsicibaccatum and S. circaeifolium ssp. quimense Accessions

To identify resistant genotypes to be used as parents for crossing with susceptible plants, several accessions of the wild species $S$. capsicibaccatum and of both $S$. circaeifolium subspecies were screened for resistance to $P$. infestans isolate 90128 . At least two plants per accession were tested (Table 1). For $S$. capsicibaccatum, 40 plants from eight accessions were tested. Two genotypes showed resistance to $P$. infestans, one was from accession 536 and the other one was from accession 334. For $S$. circaeifolium, 30 plants from six accessions were tested and the majority of these, 
22, were resistant. It seems, therefore, that resistance to P. infestans isolate 90128 is the rule in S. circaeifolium and the exception in S. capsicibaccatum.

\section{Population Development and Spectrum of Late Blight Resistance}

The resistant genotypes cap536-1 and qum567-1 from $S$. capsicibaccatum and $S$. circaeifolium ssp. quimense, respectively, were crossed with the susceptible $S$. circaeifolium ssp. circaeifolium crc564-3 and crc564-4, respectively. A detached leaf assay performed on the F1 plants allowed an unambiguous classification of resistant and susceptible phenotypes (Fig. 1). The segregation of the resistance in the two populations followed a 1:1 ratio $(p<0.05)$ which is consistent with the presence of single dominant $R$ genes Rpi-capl and Rpi-quml in the resistant parental plants cap536-1 and qum567-1, respectively (Table 2). The resistance spectra of the resistant parental genotypes cap536-1 and qum567-1 were determined by challenging them with 21 isolates of different complexity and geographic provenance (Table 3 and S1). Both genotypes were resistant to all 21 isolates tested, indicating that they have a

Table 3 Resistance phenotypes observed after inoculations with Phytophthora infestans isolates on the parents of the F1 populations (cap536-1, qum567-1, crc564-3, and crc564-4), and 10 resistant and 10 susceptible F1 genotypes from the Rpi-capl population in detached leaf assays

\begin{tabular}{lllllll}
\hline P.i. isolate & cap536-1 & crc564-3 & 10 R F1 & 10 S F1 & qum567-1 & crc564-4 \\
& Rpi-cap1 & rpi-cap1 & Rpi-cap1 & rpi-cap1 & Rpi-qum1 & rpi-qum1 \\
\hline VK98014 & $\mathrm{R}$ & $\mathrm{S}$ & $\mathrm{R}$ & $\mathrm{S}$ & $\mathrm{R}$ & $\mathrm{S}$ \\
IPO428-2 & $\mathrm{R}$ & $\mathrm{S}$ & $\mathrm{R}$ & $\mathrm{S}$ & $\mathrm{R}$ & $\mathrm{S}$ \\
NL01096 & $\mathrm{R}$ & $\mathrm{S}$ & $\mathrm{R}$ & $\mathrm{S}$ & $\mathrm{R}$ & $\mathrm{S}$ \\
EC1 & $\mathrm{R}$ & $\mathrm{S}$ & $\mathrm{R}$ & $\mathrm{S}$ & $\mathrm{R}$ & $\mathrm{S}$ \\
90128 & $\mathrm{R}$ & $\mathrm{S}$ & $\mathrm{Nd}$ & $\mathrm{Nd}$ & $\mathrm{R}$ & $\mathrm{S}$ \\
NL00228 & $\mathrm{R}$ & $\mathrm{S}$ & $\mathrm{Nd}$ & $\mathrm{Nd}$ & $\mathrm{R}$ & $\mathrm{S}$ \\
F95573 & $\mathrm{R}$ & $\mathrm{S}$ & $\mathrm{Nd}$ & $\mathrm{Nd}$ & $\mathrm{R}$ & $\mathrm{S}$ \\
H30P04 & $\mathrm{R}$ & $\mathrm{R}$ & $\mathrm{Nd}$ & $\mathrm{Nd}$ & $\mathrm{R}$ & $\mathrm{R}$ \\
USA618 & $\mathrm{R}$ & $\mathrm{R}$ & $\mathrm{Nd}$ & $\mathrm{Nd}$ & $\mathrm{R}$ & $\mathrm{R}$ \\
IPO-C & $\mathrm{R}$ & $\mathrm{R}$ & $\mathrm{Nd}$ & $\mathrm{Nd}$ & $\mathrm{R}$ & $\mathrm{R}$ \\
PIC99183 & $\mathrm{R}$ & $\mathrm{R}$ & $\mathrm{Nd}$ & $\mathrm{Nd}$ & $\mathrm{R}$ & $\mathrm{R}$ \\
PIC99177 & $\mathrm{R}$ & $\mathrm{R}$ & $\mathrm{Nd}$ & $\mathrm{Nd}$ & $\mathrm{R}$ & $\mathrm{R}$ \\
PIC99189 & $\mathrm{R}$ & $\mathrm{R}$ & $\mathrm{Nd}$ & $\mathrm{Nd}$ & $\mathrm{R}$ & $\mathrm{R}$ \\
IPO-0 & $\mathrm{R}$ & $\mathrm{Nd}$ & $\mathrm{Nd}$ & $\mathrm{Nd}$ & $\mathrm{R}$ & $\mathrm{Nd}$ \\
UK7824 & $\mathrm{R}$ & $\mathrm{Nd}$ & $\mathrm{Nd}$ & $\mathrm{Nd}$ & $\mathrm{R}$ & $\mathrm{Nd}$ \\
88133 & $\mathrm{R}$ & $\mathrm{Nd}$ & $\mathrm{Nd}$ & $\mathrm{Nd}$ & $\mathrm{R}$ & $\mathrm{Nd}$ \\
91011 & $\mathrm{R}$ & $\mathrm{Nd}$ & $\mathrm{Nd}$ & $\mathrm{Nd}$ & $\mathrm{R}$ & $\mathrm{Nd}$ \\
88069 & $\mathrm{R}$ & $\mathrm{Nd}$ & $\mathrm{Nd}$ & $\mathrm{Nd}$ & $\mathrm{R}$ & $\mathrm{Nd}$ \\
NL05-194 & $\mathrm{R}$ & $\mathrm{Nd}$ & $\mathrm{Nd}$ & $\mathrm{Nd}$ & $\mathrm{R}$ & $\mathrm{Nd}$ \\
CA-65 & & $\mathrm{R}$ & $\mathrm{Nd}$ & $\mathrm{Nd}$ & $\mathrm{Nd}$ & $\mathrm{R}$ \\
$3128-A$ & $\mathrm{R}$ & $\mathrm{Nd}$ & $\mathrm{Nd}$ & $\mathrm{Nd}$ & $\mathrm{R}$ & $\mathrm{Nd}$ \\
\hline & & & & &
\end{tabular}

$R$ resistant, $S$ susceptible, $N d$ not determined 
similar broad resistance spectrum. Genotypes crc564-3 and crc564-4, used for the crosses that were susceptible to isolate 90128, showed resistance to several other isolates (Table 3), which suggests that additional $R$ genes are present in $S$. circaeifolium. As a consequence, to test the segregation of Rpi-capl and Rpi-quml in the two F1 populations, only the isolates that were virulent on the two $S$. circaeifolium ssp. circaeifolium genotypes (crc564-3 and crc564-4) could be used.

\section{Mapping and Fine Mapping of Rpi-capl}

In a previous study by Jacobs et al. (2010) on the same F1 population of cap563-1 $\times$ crc564-3, Rpi-capl was shown to be located in the $N$ cluster at the distal end of the short arm of chromosome 11. They identified the map position by NBS profiling and could link the resistance phenotype to the CAPS marker Cp58 with one recombinant out of $20 \mathrm{~F} 1$ individuals. To confirm the map position and to construct a more robust genetic map, we phenotyped 108 F1 individuals of the Rpi-capl population for resistance to $P$. infestans isolate 90128 . The linkage of Rpi-capl with CAPS marker Cp58 was confirmed. Only two recombinants were found in a set of 91 individuals. Markers previously mapped in the $N$ cluster in $S$. tuberosum were also tested. Six out of seven primer combinations tested gave amplification on the resistant genotypes, and only two resulted in polymorphism. These were markers N127 (Marczewski et al. 2001), derived from the NL-27 cDNA, and M33 (Brigneti et al. 1997). In parallel, markers were developed using sequence information available from the RH physical map on chromosome 11 (Bakker et al. 2011). Primers, designed on these BAC sequences, were applied to the DNA of cap536-1 and crc564-3. Out of 17 primer pairs giving PCR amplification in RH, only five gave an amplification product on the cap536-1 and qum567-1 genotypes, and only two resulted in CAPS markers: T179 and T081. Table 4 summarizes the markers developed for the Rpi-capl population.

Table 4 PCR markers for the F1 mapping populations of Rpi-capl (cap) and Rpi-quml (qum), with primer sequences based on BAC sequences located on the long arm of chromosome 11 from the reference genotype $\mathrm{RH}$ or references for primers already published, annealing temperature in ${ }^{\circ} \mathrm{C}(\mathrm{TM})$, and restriction enzyme to identify a polymorphism for each population

\begin{tabular}{lllll}
\hline Marker & Sequence $^{\text {a }}$ or reference & TM & \multicolumn{2}{l}{ Enzyme } \\
\cline { 3 - 5 } & & & cap & qum \\
\hline N127 & Marczewski et al. 2001 & 55 & a.s. & XapI \\
M33 & Brigneti et al. 1997 & 62 & AluI & - \\
ADG2 & Hämäläinen et al. 1998 & 55 & - & PsuI \\
T081 & F GTTGGGCAGGTACTCAATGG & 55 & MseI & HpyF3I \\
T179 & R ATTCAGGACGGGTCATTAGG & & & AluI \\
Fir300F-Hinc & F CTAGCTCTGTCCCCGTCCAC & 55 & & HincI \\
Nbs15F-BspL & ATGCATGAYTTRATWVAAGABATGGG & 55 & BspLI & - \\
\hline
\end{tabular}

${ }^{\text {a }}$ Sequences of primers designed in this study 
In total, five markers (Cp58, N127, M33, T179, and T081) were developed that could be used to construct the genetic map of the Rpi-capl region based on a population of 108 individuals. The markers Cp58 and N127 were on one side, T081 and T179 were on the other side of the gene, and M33 was co-segregating with Rpicapl (data not shown). This allowed to pursue a genetic fine mapping approach since the flanking markers could be used for a recombinant screen. Eight hundred fortyeight individuals were screened with the flanking markers Cp58, N127, and T179. The sequence-characterized amplified region (SCAR) marker N127 was multiplexed with the M33 primer pair as internal control to test for DNA quality and falsenegative amplification. In total, 792 plants out of 848 could be scored for these three markers. Nine 96-well plates were screened and each plate is referred to as a series. In the first two series of screening, more recombinants were identified between the marker N127 and Rpi-cap1, than between Cp58 and Rpi-cap1, suggesting that N127 was further away from the gene than Cp58. So, in the last seven series, only N127 and T179 were used. In total, 85 recombinants were detected, phenotyped, and regenotyped after CTAB DNA isolation. Out of the 85 recombinants, only $14 \mathrm{~F} 1$ individuals were confirmed as true recombinants. False recombinants were mainly due to the SCAR marker N127. Later, also, the remaining markers M33 and T081 were tested on the newly identified recombinants. The recombinant population $(n=$ 792), combined with the initial F1 population $(n=108)$, represents a total population of 900 individuals. The genetic map of this Rpi-capl population is presented in Fig. 2. The closest flanking markers to Rpi-capl are the markers N127 and M33, both $0.1 \mathrm{cM}$ (one recombinant) away on either side of the gene. In the population of 108 individuals, the distance between Rpi-capl and N127 appeared larger because of false positives. The Cp58 marker mapped $0.9 \mathrm{cM}$ (eight recombinants) distal to N127.

\section{High-Resolution Mapping of Rpi-qum1}

Similarly as for Rpi-cap1, the mapping position of Rpi-qum1 was hypothesized to be located on chromosome 11 because of a linked NBS profile marker with homology to $N$-like sequences. We characterized 53 individuals of the Rpi-qum1 mapping population with $P$. infestans isolate 90128 . To confirm the presumed mapping position, the markers linked to Rpi-cap1 population were also tested on the Rpi-qum1 population. Unfortunately, Cp58 and M33 were not polymorphic in the Rpi-qum1 population. Only N127 was polymorphic and segregated in the Rpi-qum1 population. Therefore, an additional known marker ADG2 (Hämäläinen et al. 1998) was tested and was found to be polymorphic and segregating in the Rpi-qum1 population. Unfortunately, ADG2 was not polymorphic in the Rpi-capl population. The primers designed on the RH sequences did not give any PCR products, like it was the case in the Rpi-capl population. A segregating polymorphism was found only for marker T081. The marker N127 was linked to Rpi-qum1 with one recombinant, T081 was on the other side of the Rpi-qum1 with two recombinants, and ADG2 was distal to T081 and the gene with four additional recombinants, in a population of 53 individuals (data not shown). It is therefore confirmed that Rpi-qum1 maps to a syntenic locus as Rpi-cap1. In order to achieve fine mapping, a recombinant screen was performed with the markers N127, T081, and ADG2 on 349 individuals of the Rpi-qum1 population. In total, 306 plants could be scored with at least two markers and 21 recombinants were initially 


\section{Rpi-cap1}

\section{Rpi-qum1}

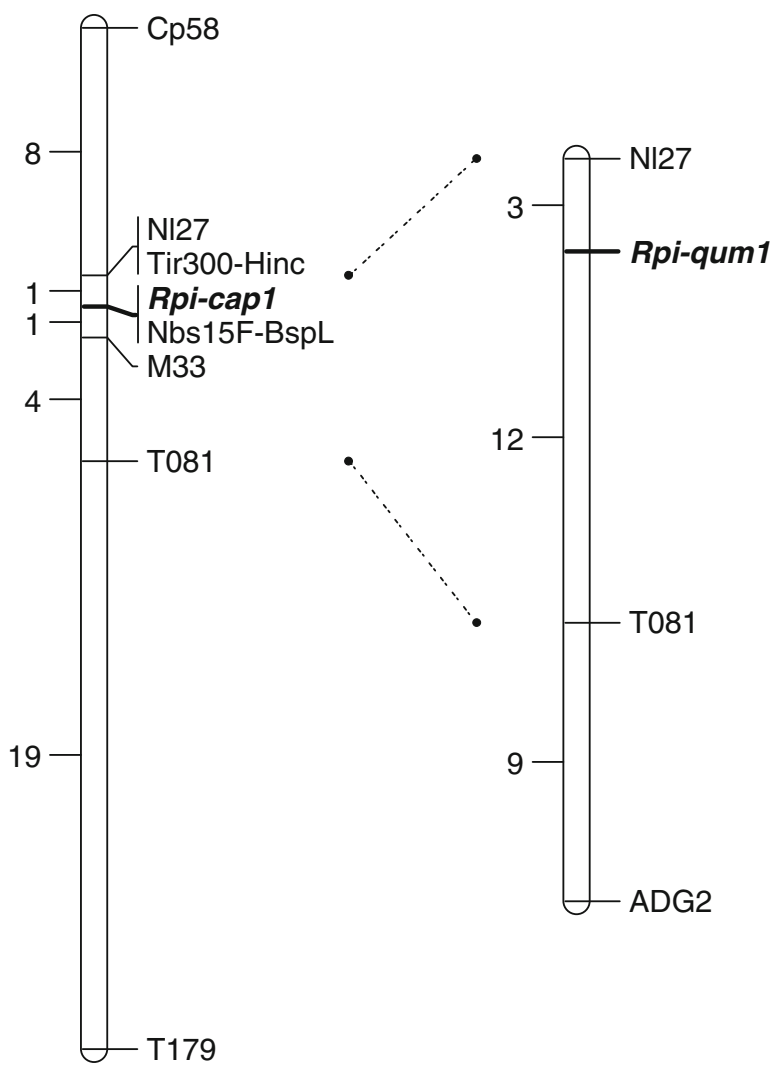

Fig. 2 The genetic maps of Rpi-cap1 and Rpi-qum1 on chromosome 11. The numbers on the left indicate the number of recombinants out of 900 individuals for Rpi-cap1 and 306 for Rpi-qum1. Most markers are CAPS markers except Nbs15F-BspL and Tir300-Hinc that are $N$-like profiling markers and N127 in the Rpicap1 population which is an allele-specific marker. The dotted lines connect the markers present in both populations

found between the markers N127 and ADG2. Recombinants were re-genotyped and 16 could be confirmed. The 16 confirmed recombinants were maintained in in vitro culture and their resistance phenotype was tested at least twice by DLA. The genetic map of Rpi-qum 1 resulting from that analysis is given in Fig. 2. In the population of 360 individuals, the markers N127 and ADG2 were $6.7 \mathrm{cM}$ away from each other (24 recombinants). The closest flanking markers were N127 and T081, which were located $0.8 \mathrm{cM}$ (three recombinants) distal and $2.5 \mathrm{cM}$ (12 recombinants) proximal to Rpi-qum1, respectively.

Development of Co-Segregating $N$-Like Profiling Marker

Since Rpi-capl and Rpi-quml are presumed to locate in an $N$-like gene cluster, we developed markers on the basis of $N$-gene-specific sequences. We performed this study on Rpi-capl as we here had at our disposal the larger of the two populations. The $N$-like profiling approach was done by following the NBS profiling protocol (van 
der Linden et al. 2004) and substituting the NBS degenerate primers for degenerate $N$-like primers (Verzaux et al. 2011). From the 40 primer enzyme combinations tested, 21 markers were identified on the bulks and 10 were confirmed on the individuals of the bulks as linked with the resistance phenotype. Linked markers were identified on both sides of the gene, indicating that the $N$ cluster is extending on both sides of the gene. Only the two closest linked markers, Tir300FHinc and Nbs15F-BspL, were added to the genetic map (Fig. 2). Marker Tir300-Hinc had one recombinant with Rpi-capl and was co-segregating with marker N127. Marker Nbs15F-BspL co-segregated with the resistance in 900 individuals (Fig. 3). This confirmed that $N$ homologous sequences are located near Rpi-capl as well as to Rpi-qum 1 and shows that the resistance genes Rpi-capl and Rpi-qum1 are located in an $N$-like gene cluster, suggesting that Rpi-capl and Rpi-qum 1 are homologous to $N$ as well.

\section{Discussion}

Resistance to $P$. infestans in the studied genotypes of wild Bolivian accessions of Solanum species $S$. capsicibaccatum and $S$. circaeifolium ssp. quimense is monogenic and is conferred by dominant genes designated Rpi-capl and Rpi-qum1, respectively. Both genes are located in the $N$ cluster on chromosome 11. Segregating F1 populations, generated by crossing the selected resistant genotypes with susceptible genotypes, was characterized and CAPS markers from the $N$ cluster were developed to construct a genetic map of the region where both $R$ genes were located. Next step was to screen for individuals with recombination events between flanking markers to fine map the gene more precisely. The plants with the closest recombination events to Rpicapl were used to develop an $N$-like-specific marker fully co-segregating with the resistance. This marker can be very useful for future cloning of Rpi-capl. To date, the first functional potato $R$ gene located on the long arm of chromosome 11 in the $N$ cluster has yet to be cloned (Hein et al. 2009). RH BAC sequences and potato genome sequences (http://www.potatogenome.net) revealed that many $R$ gene homologs are present in the $N$ cluster, and since gene sequence homologies vary considerably, an allele mining approach as described by Pel et al. (2009) is not feasible. A map-based cloning approach is probably the most appropriate strategy to follow and should be successful as the phenotypic resistance contrast between genotypes is large even though the levels of polymorphism and heterozygosity are relatively low. Rpi-

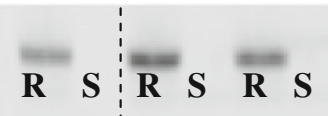
Parents $\quad$ Bulks

\section{S S R S nd R R S R R R R S R R S R S S R S}

Fig. 3 An $N$-like profiling marker co-segregating with the resistance in $900 \mathrm{~F} 1$ individuals from the Rpicapl population. It was generated with primer $\mathrm{Nbs} 15 \mathrm{~F}$ in combination with the enzyme BspLI. The phenotype is indicated with $R$ for resistant and $S$ for susceptible. On the left: Screen of the bulks of 10 resistant and susceptible F1 plants, respectively. From left to right: the parents, bulks with non-recombinant F1 plants, bulks with F1 plants recombined between the closest markers to the gene. On the right: Individual F1 plants including the ones with recombination events close to Rpi-cap1. The fourth F1 genotype had a susceptible phenotype and did not contain the marker band of the right size; however, a fragment was observed that was one nucleotide longer 
capl and Rpi-qum1 have a very wide resistance spectrum as they are resistant to all 21 isolates tested so far and are thus very interesting genes to include in breeding programs.

In the tested accessions of $S$. capsicibaccatum, the occurrence of resistance to late blight isolate 90128 is an exception, whereas in those of $S$. circaeifolium ssp. quimense, it is more the rule. These observations suggest that the occurrence of the resistance in $S$. circaeifolium ssp. quimense is well established. In addition to Rpicapl and Rpi-qum1, additional resistance was identified in S. circaeifolium ssp. circaeifolium. Altogether, these data suggest a strong disease pressure in the locations where $S$. circaeifolium accessions were collected, especially for $S$. circaeifolium ssp. quimense. Plants containing $R$ genes have a selective advantage in regions favorable for late blight infections and the gene is more easily maintained then in regions where late blight is less frequently occurring.

The wild diploid tuber-bearing species $S$. capsicibaccatum and $S$. circaeifolium ssp. quimense are not closely related to $S$. tuberosum. However, hybridization with diploid genotypes of $S$. tuberosum is possible resulting in F1 individuals with different ploidy levels (Louwes et al. 1992). Therefore, in this study, the resistant genotypes were crossed with susceptible genotypes from the series Circaeifolia. Marker development was hampered because of a large difference between the $S$. tuberosum sequences used to design the primers and the genomic DNA of the series Circaeifolia on which these primers were applied. Crosses, although inter-specific, are within the series Circaeifolia, which in this case implied a relatively low level of polymorphism. So, from the large number of primer combinations designed on the $S$. tuberosum RH sequences, the relatively few primer combinations that gave amplification products on the wild species were often not polymorphic. The small phylogenetic distance within the series Circaeifolia renders the development of markers to be difficult because of the absence of a sufficient amount of polymorphism. The large phylogenetic distance between these wild species and $S$. tuberosum limits the application of reference genome sequence information in the latter species to speed up the cloning process of $R$ genes from the series Circaeifolia.

Limitations in marker development would make the chromosome walking step of the map-based cloning approach quite challenging. So, the development of a marker co-segregating with the resistance in a large population is very helpful and could be used for BAC landing. The Rpi-capl population was more suitable for that analysis than the Rpi-qum 1 population as the available population was larger. $N$-like profiling is a CDP approach, derived from NBS profiling, used to identify markers closely linked to $R$ genes in the $N$ cluster on chromosome 11. $N$-like profiling was also successfully applied to map a late blight $R$ gene from Solanum avilesii (Rpi-avll; Verzaux et al. 2011) and from Solanum edinense (Rpi-edn3; Verzaux 2010). Variants of the CDP technique were recently used to specifically tag $R$ gene homologs from Tm- $2^{2}$, Sw5, Hero, and $R 2$ gene clusters, for the mapping of the $R 8$ late blight resistance gene from Solanum demissum (Jo et al. 2011). The current study clearly shows that CDP profiling is not only suitable for mapping but also for fine mapping of $R$ genes. Because of the presence of multiple copies of $R$ gene homologs in $R$ gene clusters, high marker saturation in the genomic region of interest is obtained and can efficiently be pursued. In a follow-up research, closely linked or co-segregating CDP markers could be used for BAC landing and BAC walking purposes. It remains, 
however, to be shown how effective this works. Upon screening of a BAC library, different target complexities will be encountered as compared to profiling of a full genome, which might result in amplification of different set of polymorphic bands. Our own unpublished results show that this problem can be overcome by appropriate dilutions of the restriction ligation reactions, prior to PCR amplification. Overall, it is concluded that CDP can be very useful to speed up the genetic and physical mapping and BAC walking.

The very similar mapping positions of Rpi-capl and Rpi-qum1, the small phylogenetic distance between the two species, their resistance spectrum, and their common geographic origin suggest that they could be the same gene or alleles of the same gene. Rpi-avl1 from the wild species $S$. avilesii from the series Tuberosa also maps on chromosome 11 in the same $N$-like cluster (Verzaux et al. 2011). A resistance gene from $S$. edinense (Rpi-edn3), which shows a similar recognition specificity as $R 4$ from $S$. demissum, also maps on chromosome 11 in the $N$ cluster (Verzaux 2011). Both $R 4$ and Rpi-avll have a different, non-overlapping, isolate resistance spectrum than Rpi-capl and Rpi-qum1. It shows that Rpi genes mapped in the same cluster can have different specificities as also has been observed in the $R 3$ cluster with the $S$. demissum $R 3 a$ and $R 3 b$ genes (Huang et al. 2005a, b; Li et al. 2011) and in the $R 2$ cluster with the $R 2$ family and Rpi-mcd1 (Lokossou et al. 2009).

Two major genes conferring resistance to $P$. infestans from wild Solanum species can now be added to the $N$ cluster, a hotspot for resistance to many pathogens on chromosome 11 (Gebhardt and Valkonen 2001). Because of their map position in the $N$ cluster, Rpi-capl and Rpi-qum1 can be hypothesized to belong to the TIR-NBSLRR class, similar to the $N$ gene. They would be the first major genes conferring resistance to $P$. infestans from that class, as all cloned Rpi genes so far belong to the CC-NBS-LRR class (Hein et al. 2009). The $R$ genes present in $S$. capsicibaccatum and $S$. circaeifolium ssp. quimense appear to be very useful for resistance breeding programs applying a cisgenic approach (Jacobsen and Schouten 2007; Schouten and Jacobsen 2008). Cisgenes are defined as natural genes with their own expression elements that originate from the same plant species or from crossable species. The series Circaeifolia was suggested to be a rather primitive, geographically, and phylogenetically isolated series (Hawkes and Hjerting 1989) and was reported to only rarely intercross with species from other series (Louwes et al. 1992). However, successful crosses with other series, Tuberosa in particular, have been described: the species $S$. capsicibaccatum and $S$. circaeifolium ssp. quimense could both successfully be crossed with Solanum lignicaule from the series Tuberosa and with di(ha) ploid clones from S. tuberosum resulting in true hybrids (Chavez et al. 1988). However, many rounds of backcrosses are anticipated before the resistance traits can be introgressed into a potato cultivar. Therefore, after cloning, Rpi-capl and Rpi-qum 1 would qualify as cisgenes that are preferably introduced into selected potato cultivars by genetic modification. Co-introduction with other Rpi genes to obtain a compilation of $R$ genes might make it nearly impossible for $P$. infestans to overcome the resistance.

Acknowledgments We thank Dr. Hendrik Rietman, Wageningen UR Plant Breeding, for testing parental genotypes with $P$. infestans isolates. 
Open Access This article is distributed under the terms of the Creative Commons Attribution License which permits any use, distribution, and reproduction in any medium, provided the original author(s) and the source are credited.

\section{References}

Bakker E, Borm T, Prins P, van der Vossen E, Uenk G, Arens M, de Boer J, van Eck H, Muskens M, Vossen J, van der Linden G, van Ham R, Klein-Lankhorst R, Visser R, Smant G, Bakker J, Goverse A (2011) A genome-wide genetic map of NB-LRR disease resistance loci in potato. Theor Appl Genet 123:493-508

Brigneti G, GarciaMas J, Baulcombe DC (1997) Molecular mapping of the potato virus Y resistance gene Ry (sto) in potato. Theor Appl Genet 94:198-203

Chavez R, Jackson MT, Schmiediche PE, Franco J (1988) The importance of wild potato species resistant to the potato cyst nematode, Globodera pallida, pathotypes P4A and P5A, in potato breeding. II. The crossability of resistant species. Euphytica 37:15-22

Chisholm ST, Coaker G, Day B, Staskawicz BJ (2006) Host-microbe interactions: shaping the evolution of the plant immune response. Cell 124:803-814

Flor HH (1971) Current status of gene-for-gene concept. Ann Rev Phytopathol 9:275

Gebhardt C, Valkonen JPT (2001) Organization of genes controlling disease resistance in the potato genome. Ann Rev Phytopathol 39:79-102

Hämäläinen JH, Sorri VA, Watanabe KN, Gebhardt C, Valkonen JPT (1998) Molecular examination of a chromosome region that controls resistance to potato $\mathrm{Y}$ and A potyviruses in potato. Theor Appl Genet 96:1036-1043

Haverkort AJ, Boonekamp PM, Hutten R, Jacobsen E, Lotz LAP, Kessel GJT, Visser RGF, Van Der Vossen EAG (2008) Societal costs of late blight in potato and prospects of durable resistance through cisgenic modification. Pot Res 51:47-57

Hawkes JG, Hjerting JP (1989) The potatoes of Bolivia: their breeding value and evolutionary relationships. Clarendon, Oxford

Hehl R, Faurie E, Hesselbach J, Salamini F, Whitham S, Baker B, Gebhardt C (1999) TMV resistance gene $N$ homologues are linked to Synchytrium endobioticum resistance in potato. Theor Appl Genet 98:379386

Hein I, Birch PRJ, Danan S, Lefebvre V, Odeny DA, Gebhardt C, Trognitz F, Bryan GJ (2009) Progress in mapping and cloning qualitative and quantitative resistance against Phytophthora infestans in potato and its wild relatives. Pot Res 52:215-227

Hogenhout SA, Van der Hoorn RAL, Terauchi R, Kamoun S (2009) Emerging concepts in effector biology of plant-associated organisms. Mol PlantMicrobe Interact 22:115-122

Huang S, Vleeshouwers VGAA, Visser RGF, Jacobsen E (2005a) An accurate in vitro assay for highthroughput disease testing of Phytophthora infestans in potato. Plant Disease 89:1263-1267

Huang S, van der Vossen EAG, Kuang H, Vleeshouwers VGAA, Zhang N, Borm TJA, van Eck H, Baker $\mathrm{B}$, Jacobsen E, Visser RGF (2005b) Comparative genetics facilitates the cloning of the $R 3 a$ late blight resistance gene in potato. Plant $\mathrm{J}$ 42:251-261

Jacobs MMJ, Vosman B, Vleeshouwers VGAA, Visser RGF, Henken B, van den Berg RG (2010) A novel approach to locate Phytophthora infestans resistance genes on the potato genetic map. Theor Appl Genet 120:785-796

Jacobsen E, Schouten HJ (2007) Cisgenesis strongly improves introgression breeding and induced translocation breeding of plants. Trends Biotechnol 25:219-223

Jo KR, Arens M, Kim TY, Jongsma MA, Visser RGF, Jacobsen E, Vossen JH (2011) Mapping of the $S$. demissum late blight resistance gene $R 8$ to a new locus on chromosome IX. Theor Appl Genet 123 (8):1331-1340

Leister D, Ballvora A, Salamini F, Gebhardt C (1996) A PCR-based approach for isolating pathogen resistance genes from potato with potential for wide application in plants. Nature Genet 14:421-429

Li G, Huang S, Guo X, Li Y, Yang Y, Guo Z, Kuang H, Rietman H, Bergervoet M, Vleeshouwers VGAA, van der Vossen E, Qu D, Visser RGF, Jacobsen E, Vossen JH (2011) Cloning and characterization of $R 3 b$; members of the $R 3$ superfamily of late blight resistance genes show sequence and functional divergence. Mol Plant Microbe Interact 24:1132-1142

Lokossou A, Park T-H, van Arkel G, Ruyter-Spira C, Morales J, Birch P, Visser RGF, Jacobsen E, van der Vossen E (2009) Exploiting knowledge of $R / A v r$ genes to rapidly clone a new LZ-NBS-LRR family of late blight resistance genes from potato linkage group IV. Mol Plant Microbe Interact 22:630-641 
Louwes KM, Hoekstra R, Mattheij WM (1992) Interspecific hybridization between the cultivated potato Solanum tuberosum subspecies tuberosum L. and the wild species $S$. circaeifolium subsp, circaeifolium Bitter exhibiting resistance to Phytophthora infestans (Mont.) de Bary and Globodera pallida (Stone) Behrens. Theor Appl Genet 84:362-370

Marczewski W, Flis B, Syller J, Schafer-Pregl R, Gebhardt C (2001) A major quantitative trait locus for resistance to Potato leafroll virus is located in a resistance hotspot on potato chromosome $\mathrm{XI}$ and is tightly linked to $N$-gene-like markers. Mol Plant Microbe Interact 14:1420-1425

McDonald BA, Linde C (2002) The population genetics of plant pathogens and breeding strategies for durable resistance. Euphytica 124:163-180

McDowell JM, Woffenden BJ (2003) Plant disease resistance genes: recent insights and potential applications. Trends Biotechnol 21:178-183

Michelmore RW, Meyers BC (1998) Clusters of resistance genes in plants evolve by divergent selection and a birth-and-death process. Genome Res 8:1113-1130

Pel M, S Foster, T-h Park, H Rietman, G van Arkel, J Jones, E Jacobsen, RGF Visser, E van der Vossen (2009). Mapping and cloning of late blight resistance genes from Solanum okadae and S. neorossii using a candidate gene approach. MPMI 22:601-615

Pink DAC (2002) Strategies using genes for non-durable disease resistance. Euphytica 124:227-236

Rairdan G, Moffett P (2007) Brothers in arms? Common and contrasting themes in pathogen perception by plant NB-LRR and animal NACHT-LRR proteins. Microbes Infect 9:677-686

Sarfatti M, Abuabied M, Katan J, Zamir D (1991) RFLP mapping of I1, a new locus in tomato conferring resistance against Fusarium oxysporum f. sp. lycopersici race 1. Theor Appl Genet 82:22-26

Schouten HJ, Jacobsen E (2008) Cisgenesis and intragenesis, sisters in innovative plant breeding. Trends Plant Sci 13:260-261

Schouten HJ, Krens FA, Jacobsen K, Jacobsen E (2006) Cisgenic plants are similar to traditionally bred plants - international regulations for genetically modified organisms should be altered to exempt cisgenesis. EMBO Rep 7:750-753

van der Linden CG, Wouters D, Mihalka V, Kochieva EZ, Smulders MJM, Vosman B (2004) Efficient targeting of plant disease resistance loci using NBS profiling. Theor Appl Genet 109:384-393

Verzaux E (2010) Resistance and susceptibility to late blight in Solanum: gene mapping, cloning and stacking. PhD Thesis Wageningen University

Verzaux E, Budding D, de Vetten N, Niks R, Vleeshouwers VGAA, van der Vossen EAG, Jacobsen E, Visser RGF (2011) High resolution mapping of a novel late blight resistance gene Rpi-avll, from the wild Bolivian species Solanum avilesii. Am J of Pot Res 88(6):511-519

Vidal S, Cabrera H, Andersson RA, Fredriksson A, Valkonen JPT (2002) Potato gene $Y-1$ is an $N$ gene homolog that confers cell death upon infection with potato virus Y. Mol Plant Microbe Interact 15:717-727

Vleeshouwers V, van Dooijeweert W, Keizer LCP, Sijpkes L, Govers F, Colon LT (1999) A laboratory assay for Phytophthora infestans resistance in various Solanum species reflects the field situation. Eur J Plant Pathol 105:241-250

Wang H, Qi MQ, Cutler AJ (1993) A simple method of preparing plant-samples for PCR. Nucl Acids Res 21:4153-4154

Whitham S, Dinesh-Kumar SP, Choi D, Hehl R, Corr C, Baker B (1994) The product of the tobacco mosaic virus resistance gene $N$ : similarity to toll and the interleukin-1 receptor. Cell 78:1101-1115

Zhang XC, Gassmann W (2007) Alternative splicing and mRNA Levels of the disease resistance gene RPS4 are induced during defense responses. Plant Phys 145:1577-1587 